\title{
IIRTBT RELATIVE STUDY OF WORK-LIFE STABILITY ON PUBLIC WITH PRIVATE EDUCATOR WITH REFERENCE TO COIMBATORE
}

\author{
S. Raja Sharmila*, B. Geetha Lavanya \\ Department of Commerce, Sri Ramakrishna College of Arts \& Science for Women, Bharathiar University, \\ Coimbatore, India \\ *Corresponding Author's Email: srsharmibalaji@gmail.com
}

\begin{abstract}
There is no distinction between work and life in this technology world, work-life balance plays a significant role in our day-to-day life to ensure our life, work is incredibly important so as that everybody runs behind the work there isn't any time working out with the family, health, and assemble with relatives and friends even though our food can't be chewed properly. In those days people worked harder and had enough time to spend with their families and relatives they don't even know the meaning of word accent. But in the current scenario excessive work is dumped to teachers to urge for good results. Teaching could be a profession that needs countless patience and sympathy. When the pressure falls on the teachers the identical pressure falls on the students. The teachers become stressed, and the condition of the students also become depressed. Nowadays, teachers are digitally connected with technology and talking with technology through online classes. These types of requirements are not equal to various sectors of the working classes. The main aim of this study is regarding the work-life balance, time management, income level and health. In this paper, the authors were putting to discuss the comparative study of a work-life balance on public and private teachers, and also suggest that there should be time-space to complete each work, and with this a proper tool was used in the study, and therefore, the study is conducted within Coimbatore region.
\end{abstract}

\section{Keywords: Work-Life Balance; Time Management; Income Level; Health}

\section{INTRODUCTION}

Work life balance is a method to assist balancing the life and health at workplaces and as well as living place. It gives a concept to allocating time and giving priority with a systematic manner. The aim of the study is to vary over of WLB among teachers. Most of them are having thoughts like teaching job is a stress-free job. But in real the most stressful job is teaching, because in the present scenario in teaching field, only minimum percentage of work done which is relatively for teaching, remaining non-teaching work has to be completed. And there is no leisure time for teachers in an institution. Nowadays teachers are becoming like an educated labor, and even they couldn't find time to relax in their living in home too. They have to work in home to complete their tasks. So automatically stress is created. Then how can they balance their work with life. This study helps to grant a plan to allocate their gracious time to prior work and similarly as life. To acquire an ideal harmony among work and life is critical as it requires a greater number of changes and requests a ton of obligation to both work, life, and different duties. Work life awkward nature as a rule emerge because of absence of satisfactory opportunity to oversee work responsibilities just as family and individual duties. Satisfying the contending requests of family and work isn't just baffling yet additionally unpleasant, regularly prompting infection and non-attendance, and subsequently influence the efficiency of a person.

\section{Objectives}

1. To compare the work life stability of private as well as public teachers.

2. To analyze the satisfaction measures of work life balance between teachers.

3. To give suggestions and upgrade the work life balance of private teachers with public teachers.

\section{LITERATURE REVIEW}

Uddin (2013) reveals that the teachers are being influenced because of work-life balance circumstance. In his point of view if both the place that is the organization and as well as their family show good support of this course, proper service will be done on return. Goud \& Nagaraju (2013) in the observation of their study, which is related to work life balance of teaching staff, show that greater part of the teachers is feeling pressure due to inclination stress because of 
working time, backing of colleague, culture and so on. If the institutions think about the staff welfare which helps to balance their professional and personal life. Rafeeq (2015) states that work life balance is not considered as an issue since it is reasonable. Renthlei (2016) finds out that the perspective that the level of pay is additionally a significant effect on work life balance along these lines to advance the WLB, the establishments should give better compensation. Akram et al., (2017) show that the assessment is revolved around Pakistani teachers who should be offered more administrative assistance, workplaces at work, and progression openings from both the district and typical trained professionals.

\section{RESEARCH METHODLOGY}

Research methodology is an analytical method used for research purposes. Here both the essential and auxiliary information, which were collected from different journals and website, were analyzed.

\section{Tools}

Primary data collected through Simple Percentage Analysis with 50 respondents.

\section{Impact of WLB}

Poor WLB shows the common impact such as the followings:

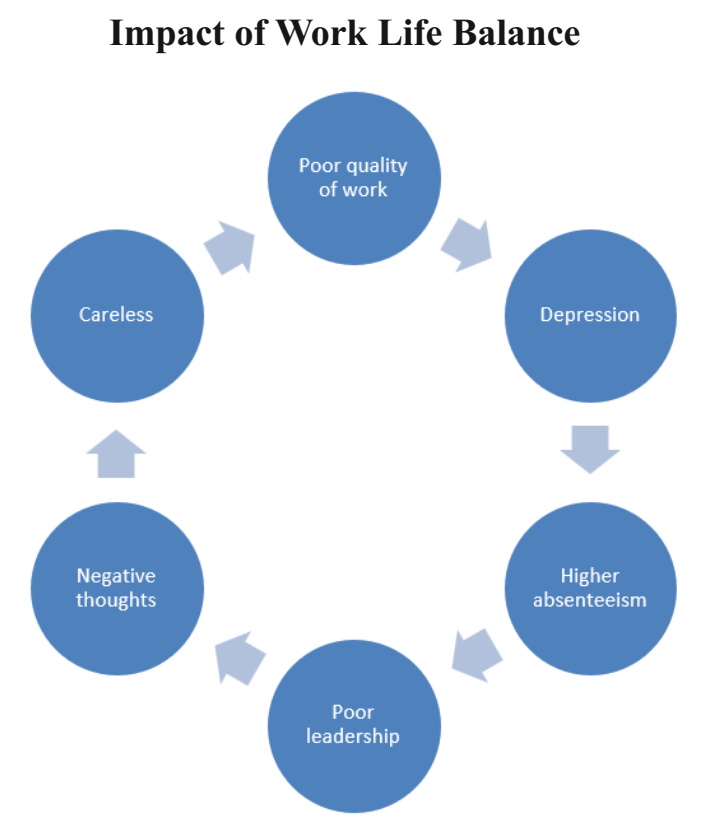

\section{Poor Quality of Work}

Poor WLB goes to forestall an individuality of an employee which will make fall their attention with work. The teacher should be perfect for ever. But during this situation they cannot act as a teacher physically and mentally. They will forget to form a schedule with proper planning. Then the results become poor quality of work.

\section{Depression}

When the teacher fails to balance their work, life gets depressed. Depression makes everything fault. Teacher should take care of their physical and mental state of being. Then only they will perform as an educator. They need to be a role model of students. The teacher should also have a captivating face with positive attitude.

\section{Higher Absenteeism}

The teachers should prepare a schedule of their work and furthermore in personal factors too. If they fail to keep it up, they will get confused and stressed. It makes higher impact like absent mind. Absent mind cannot give an attention of any work. Without attention nobody can perform anything.

\section{Poor Leadership}

"A leader is like a captain of the ship". A leader should have a leadership quality, then only he/ she can lead the team. A leader full of influence will give a good result. A frontrunner must have an empathy with an adequate knowledge to guide the team. Poor WLB will indicate poor leadership. It will collapse everything beyond this.

\section{Negative Thoughts}

Thoughts make everything. Good thoughts make good things and bad thoughts give bad things. When the teacher fails to create WLB, it seems everything happening in negative way.

\section{Carelessness}

Poor WLB makes the behavior careless. It does not make our routine work. Carelessness could not be a path to urge career. It affects the career growth and makes negative impression.

\section{WLB of Public Teachers VS Private Teachers}

The foremost cause of this study is to expose the real facts relating to public and private teachers WLB. When comparing to these two, public teachers are in safe zone whereas private teachers are being insecure in life and that they do not have proper system to accomplish their tasks so they cannot give prior participation with personal life.

Because public teachers are getting fair wages with systematic increment and additional allowances, they are merely satisfied and settled financially. Whereas 
private teachers having more work stress than the public teachers, and no proper system and time to accomplish their tasks.

\section{RESULTS \& DISCUSSION}

From the below table and graph, it can be inferred that $26 \%$ of the teachers said that ambiance, $34 \%$ of the teachers said fair wages, $27 \%$ of the teachers are stated respect and responses, and 13\% of teachers are said institution system need to be changed (refer to table $1 \&$ figure 1).

Table 1: Elements Determining Work-Life Balance

\begin{tabular}{|c|c|c|}
\hline SI.No. & Elements & Percentage \\
\hline 1 & Ambiance & $26 \%$ \\
\hline 2 & Fair wages & $34 \%$ \\
\hline 3 & Respect and responses & $27 \%$ \\
\hline 4 & Institution system & $13 \%$ \\
\hline
\end{tabular}

Figure 1: Elements Determining Work-Life Balance

\begin{tabular}{|c|}
\hline Elements Determining Work-Life Balance \\
"Ambiance $\quad$ Fair wages $=$ Respect and responses - Institution s/stem \\
\hline
\end{tabular}

\section{Measures to Improve WLB}

In this study the following measures are suggested to help motive the teachers' work life balance (refer to table $2 \&$ figure 2):

1. Professional development opportunities

2. Leadership with concern

3. Friendly work environment

4. Health and wealth provisions

5. Fair wage

6. Field trips

7. Extra monetary benefits

8. Proper allocation of time to accomplish tasks

(Goud \& Nagaraju, 2013; Renthlei, 2016).

Table 2: Estimate to Upgrade Work-Life Balance

\begin{tabular}{|c|c|c|}
\hline SI. No. & Estimate & Percentage \\
\hline 1 & Development opportunities & $27 \%$ \\
\hline 2 & Leadership with concern & $23 \%$ \\
\hline 3 & Friendly work environment & $19 \%$ \\
\hline 4 & Health and wealth provisions & $7 \%$ \\
\hline 5 & Time for task & $24 \%$ \\
\hline
\end{tabular}

Figure 2: Estimate to Upgrade Work-Life Balance

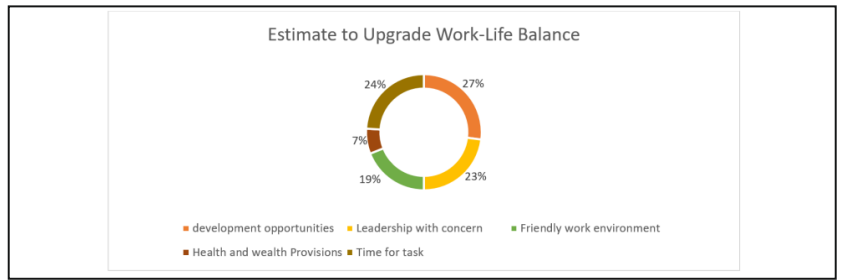

\section{CONCLUSION}

The present study reveals that the public teachers have better work health balance comparing to private teachers. Institution should introduce more measures to boost work life balance of teachers with fair wages and better ambiance. Employee health impacts in most significant way, that is why institutions should bring secure infrastructure, positive work attributes and sufficient time for tasks.

\section{Conflict of Interests}

The authors declare that they have no conflict of interest.

\section{ACKNOWLEDGMENT}

The authors express sincere gratitude to the institutional authority for completion of the work.

\section{REFERENCES}

Akram, M., Ilgan, A., Ozu, O. \& Shah, A.A. (2017). Quality of School Work Life of Public-School Teachers: Cases from Turkey and Pakistan. Journal of Education and Educational Development, 4(2), pp 246-264.

Goud, V.M. \& Nagaraju, K. (2013). Work Life Balance of Teaching Faculty with Reference to Andhra Pradesh Engineering Colleges. Global Journal of Management and Business Studies, 3(8), pp 891-896.

Rafeeq, M. (2015). Work Life Balance (WLB) Is LifeWork Balance (LWB) An Innovative Approach on Teaching Faculties in Private Rural Higher Educational Institutions. IOSR Journal of Business and Management, 17(4), pp 22-30.

Renthlei, L. (2016). A Study on the Work-Life Balance of Women Teachers in Private Un-Aided Schools of Aizawl City in Mizoram. Department of Management. Mizoram University, June. Retrieved From: http://mzuir.inflibnet.ac.in/ bitstream/ 123456789/151/1/Lalhmingliana\%20Renthlei\%20( Management).pdf

Uddin, M. (2013). Work-Life Balance: A Study on Female Teachers of Private Education Institutions of Bangladesh. European Journal of Business and Management, 5(13), pp 10-17. 